\title{
Guidelines for Personal Protection of Specific Groups from COVID-19
}

\author{
Chinese Center for Disease Control and Prevention
}

These guidelines are for the protection of individuals involved in the prevention and control of COVID-19 including the following groups: professionals who carry out epidemiological investigations; people working in isolation wards and medical observation sites; people who transport patients and infected persons and dispose of corpse; and people involved in environmental cleaning and disinfection, specimen collection, and laboratory work.

\section{PERSONAL PROTECTIVE EQUIPMENT AND ITS USE}

All persons who come into contact with or who may come into contact with COVID-19 patients and asymptomatic infected persons, their body fluids or excreta (blood, body fluids, secretions, vomitus, excreta, etc.), or contaminated items and object surfaces must use personal protective equipment including:

\section{Gloves}

When entering a contaminated area or performing diagnosis and treatment, one must wear disposable rubber or nitrile gloves according to the type of work they do. When coming into contact with a different patient or when a glove is torn or otherwise compromised, disinfection, hand hygiene, and equipping new gloves is essential.

\section{Medical Protective Masks}

When entering a contaminated area or performing diagnosis and treatment, one must wear a medical protective mask or a powered air filter respirator. Before each use, an air tightness check should be performed. When wearing multiple protective equipment items, the final step should be to remove the medical protective mask.

\section{Protective Face Shields or Goggles}

When one is entering a contaminated area or performing diagnosis and treatment and/or when one's eyes, eye conjunctiva, or face are at risk of being contaminated by blood, body fluids, secretions, excreta, and aerosols, one must wear a protective face shield or goggles. After removing reusable goggles, the goggles are to be sterilized and dried prior to next use.

\section{Protective Suits}

When entering a contaminated area or performing diagnostic and treatment, one should change his or her personal clothing and wear work clothes (surgical scrubs or disposable clothing) plus protective clothing.

\section{HAND HYGIENE}

All personnel participating in field work must use effective hand hygiene practices. An alcohol or alcohol compound-based hand-drying disinfectant rub or a 75\% ethanol solution can be used for disinfection; those allergic to alcohol can use an effective nonalcohol hand disinfectant such as quaternary ammonium disinfectant. Under special conditions, one can use a $3 \%$ hydrogen peroxide solution disinfectant, $0.5 \%$ povidone-iodine, or $0.05 \%$ chlorine-containing disinfectant to wipe or soak hands, using an appropriately long disinfection time. When there are visible contaminants on one's hands, the hands should be washed with liquid soap and running water before disinfection.

Hand hygiene measures should be strictly adhered to in daily work, especially before putting on gloves and other personal protective equipment, before performing aseptic operations on patients, after possibly touching a patient's blood, body fluids, and contaminated items or surrounding surfaces, and when removing personal protective equipment.

\section{PERSONAL PROTECTION FOR SPECIAL GROUPS}

\section{Epidemiological Investigators}

When investigating close contacts, investigators should wear disposable work caps, medical surgical masks, work clothes, and disposable gloves; 
investigators should always be at least one meter away from the person being investigated.

When investigating suspected cases, confirmed cases, and asymptomatic infected persons, one should wear work clothes, disposable work caps, disposable gloves, protective clothing, a KN95/N95 or above particulate protective mask or medical protective masks, protective face shields or goggles, work shoes or rubber boots, and waterproof boot covers.

\section{Staff in Isolation Wards and Medical Observation Sites}

Work clothes, disposable work caps, disposable gloves, protective clothing, medical protective masks or powered air filter respirators, protective face shields or goggles, work shoes or rubber boots, and waterproof boot covers are to be worn by staff in isolation wards and medical observation sites.

\section{Personnel Transporting Cases and Asymptomatic Infected Persons}

Work clothes, disposable work caps, disposable gloves, protective clothing, medical protective masks or powered air filter respirators, protective face shields or goggles, work shoes or rubber boots, and waterproof boot covers are to be worn by individuals involved in transporting cases and asymptomatic infected persons.

\section{Personnel Handling Corpses}

Work clothes, disposable work caps, disposable gloves and long-sleeved thick rubber gloves, protective clothing, KN95/N95 or above particulate protective masks or medical protective masks or powered air filter respirators, protective face shields, work shoes or rubber boots, waterproof boot covers, and waterproof aprons or waterproof isolation gowns are to be worn by personnel handling corpses.

\section{Cleaning and Disinfection Personnel}

Work clothes, disposable work caps, disposable gloves and long-sleeved thick rubber gloves, protective clothing, KN95/N95 or above particulate protective masks or medical protective masks or powered air filter respirators, protective face shields, work shoes or rubber boots, waterproof boot covers, and waterproof aprons or waterproof isolation gowns are to be worn by individuals involved in cleaning and disinfection. When using powered air-supply filter respirators, one should select a dust-and-toxicant filter box or canister according to the type of disinfectants being used and properly protect themselves from disinfectants and other chemicals.

\section{Specimen Collection Staff}

Work clothes, disposable work caps, double gloves, protective clothing, KN95/N95 or above particulate protective masks or medical protective masks or powered air filter respirators, protective face shields, work shoes or rubber boots, and waterproof boot covers are to be worn by staff involved in collection of specimens. If necessary, depending on the nature of specimen collection, one should also wear a waterproof apron or waterproof isolation gown.

\section{Laboratory Staff}

Laboratory staff should wear work clothes, disposable work caps, double gloves, protective clothing, KN95/N95 or above particulate protective masks or medical protective masks or powered air filter respirators, protective face shields or goggles, work shoes or rubber boots, waterproof boot covers. If necessary, depending on the nature of the laboratory work, one should wear a waterproof apron or waterproof isolation gown.

\section{PRECAUTIONS WHILE REMOVING PERSONAL PROTECTIVE EQUIPMENT}

1. Minimize contact with contaminated surfaces when removing personal protective equipment.

2. Non-disposable items such as protective goggles and rubber boots, once removed, should be dipped in a container of disinfectant solution. Other disposable items should be placed in a yellow medical waste collection bag for centralized disposal as medical waste.

3. Hand disinfection should be performed at each step of the process of removing protective equipment. After all protective equipment is removed, one should wash and disinfect their hands once again.

Acknowlegement: China CDC Weekly would like to thank Xijuan Fu of the WHO China Office, Lance Rodewald and Liping Wang of China CDC, and Baoying Zhang and Jin Shen of National Institute of Environment Health, China CDC for their contributions in translating and editing this document (1).

This Chinese document written by experts in China CDC Key Places Protection and Disinfection 
Technology Group for COVID-19 Emergency Response, including Liubo Zhang, Jin Shen, Hongyang Duan, Baoying Zhang, Chen Liang, and Huihui Sun of National Institute of Environment Health, China CDC.

doi: $10.46234 /$ ccdcw 2020.087
Submitted: March 10, 2020; Accepted: March 12, 2020

\section{REFERENCES}

1. Chinese Center for Disease Control and Prevention. Technical documents for COVID-19 prevention and control. http://www. chinacdc.cn/jkzt/crb/zl/szkb_11803/jszl_11815/202003/t20200309_214 241.html. [2020-3-9]. (In Chinese). 